\title{
FFPS news
}

\section{The Oryx $100 \%$ Fund}

The Society's Oryx 100\% Fund was set up in September 1971, at the suggestion of Lord Craigton, then Vice-Chairman, to provide sums of money very quickly for urgent conservation measures at home and abroad. The Society had already been providing this kind of assistance to endangered species. For example, in 1971, before the fund was launched, it gave $£ 360$ to help save the pygmy hog and hispid hare in Assam, $£ 290$ for the mountain gorilla in Rwanda, $£ 250$ for the jackass penguin in South Africa, $£ 150$ for several endangered species in Ethiopia and smaller grants for the Nile crocodile in Uganda, the Indian lion in the Gir Forest, and Kirk's red colobus monkey in Zanzibar. But it had been providing the money from small savings and there was so much more that could be done if more money were available.

The decision to appeal to members and friends only was a sound one. The only advertisement necessary was to announce the Fund in Oryx and since the Society was paying its way it could afford to donate all the money received to the conservation projects in question, deducting nothing for administrative costs. The Oryx $100 \%$ Fund still exists today, but has broadened its scope to include helping to finance University expeditions that set out to achieve worthwhile conservation objectives. The Society still appeals to its members for donations towards this work and is very grateful for their enthusiastic response. The last appeal, in the July 1988 issue, raised a welcome $£ 3000$. However, if something needs to be done urgently there is not always time to launch an appeal and wait for the outcome-the money might come too late. Therefore, the Society commits some of its core funding to $100 \%$ Fund projects, hoping to make up any shortfall later. We are taking this opportunity to remind members and friends that the Oryx $100 \%$ Fund is always open for donations, however small or large they might be.

Although we have always published in these pages the $100 \%$ Fund grants awarded at each Council Meeting, we have not always reported back on the results. Some results have appeared in these pages as short news items or as longer papers, but we intend in the future to try to pub- lish more regular news of more of the project results, starting with this issue.

\section{Grants awarded in September}

At its meeting on 21 September 1988 the FFPS Council supported the recommendations of the Grants Committee to fund the following projects.

$\mathfrak{£ 5 0 0}$ to a survey of the distribution and habitat of black lemurs Lemur macaco in coastal northwest Madagascar, where they are endemic. Total numbers are unknown, but the population is believed to be declining due to widespread deforestation for agriculture and settlement. It is hoped that the project will provide some preliminary information on the use of primary and secondary forests by black lemurs, which may be followed up later with longer-term research on the ability of the species to survive in disturbed forest.

$£ 500$ to The Cambridge Entomological Expedition to Nepal 1988 to search for and assess the habitat of the larvae of Epiophlebia laidlawi, the relict Himalayan dragonfly, which is classified as 'Vulnerable' in The IUCN Invertebrate Red Data Book. The IUCN selected this as one of this year's 'Top Twelve' endangered species. The main search will be conducted in the Shivapuri Nature Reserve, the only confirmed recent locality for the species. The team will also search near Chitre in eastern Nepal, where the dragonfly was once seen, in 1963, but where the larvae have never been found. It is critical that other sites are found for this species, which is one of only two members of the Anisozygoptera, because the existing habitats on Shivapuri are threatened by deforestation, cattle raising and the construction of a road.

$£ 250$ to continue trying to resolve the bat problem in Israel. The applicant, Dr Sandie Sowler, visited Israel at her own expense in March 1988 with letters of introduction from the FFPS and IUCN's Chiroptera Specialist Group. She talked with various authorities about the problem of using Lindane to fumigate caves in an attempt to control fruit bats, which has the incidental effect of destroying vast numbers of insectivorous bats. The problem has been a major source of international concern for some years and the authorities had been moving in the right direction, but 
Dr Sowler was able to illicit further major agreements towards stopping fumigation. The purpose of the follow-up visit is to check on the implementation of cessation of fumigation by the Israeli Department of Plant Protection and Inspection and to design a Bat Education Programme in conjunction with the Society for Protection of Nature in Israel.

In addition it was decided to make a gift of equipment to Maria Gonzalez to help in her study of the ocellated turkey Agriocharis ocellata in Guatemala's Tikal National Park. The results of her study will provide information on the habitats preferred by the species and will enable the development of a conservation strategy. The species has a relict distribution in the Yucatan Peninsula, Belize and northern Guatemala; it is threatened by habitat destruction and diseases transmitted by domestic poultry.

\section{Reports received}

Recipients of Oryx 100\% Fund grants are required to send the Society reports on completion of their research. Summaries of a few of those recently received are given here.

\section{Bolivia '87}

A team from Oxford University and the Universidad Mayor de San Andres, La Paz, Bolivia, spent six weeks in northern Bolivia collecting information on the abundance and distribution of Goeldi's monkey Callimico goeldii and other primates. Goeldi's monkey is classified as 'Rare' by the IUCN and is on Appendix 1 of CITES. Despite its wide range it has been seen infrequently by scientists, and it is probable that no protected area holds a population large enough for longterm viability. One of the two best populations for study occurs in the Pando Department of Bolivia, where it appeared to be under threat from commercial trapping and potential habitat destruction due to road building, government development plans and resettlement schemes.

The survey was conducted in an area delineated by the new $69^{\circ} \mathrm{W}$ line, the Rio Tahuamanu and the national borders with Peru and Brazil. The human residents live in small groups a few kilometres apart creating only minor disturbance 54 of the forest by their subsistence agriculture and exploitation of scattered rubber trees; they may even improve the habitat for Callimico.

Callimico was found to be more common than previously supposed in the Pando; 10 other primate species were found in the area. A reserve here, of at least $400 \mathrm{sq} \mathrm{km}$, would protect an important population of Goeldi's monkey, as well as one of the broadest spectra of primate species in the New World and five other Red Data Book species-jaguarundi, jaguar, ocelot, giant Brazilian otter and black caiman.

Reserve status would also directly benefit the human residents of the forest, who depend on the wild fauna for food and on the rubber trees for the latex. In the light of potential forest clearance, the rubber tappers, through their trade unions, have expressed interest in the maintenance of their working environment and way of life.

A major objective of the expedition was that it should be of educational value to team members from Oxford and La Paz. A link has been built between Oxford University and the Universidad Mayor de San Andres, which it is hoped will be fruitful in encouraging conservation in the Pando.

\section{El Cajas Expedition, Ecuador 1985}

Six people from the University College of North Wales visited El Cajas in southern Ecuador to collect ecological information that would assist in the formulation of a more comprehensive management plan. El Cajas, a national recreation area covering $288 \mathrm{sq} \mathrm{km}$ in the Andes near Cuenca, the country's third largest city, was established in 1977 with the objective of combining conservation, recreation and education. The main forms of human disturbance are burning and trampling, and it is imperative that these are controlled to protect the fragile vegetation and mountain soils.

The once extensive humid sub-alpine forest has been altered drastically by man and most of the vegetation is paramo grassland. There are also quinua woodlands, which are the highest woods in the world. The wide variety of animal life includes llama, deer, puma, spectacled bear, Andean fox and Andean condor. Birds of the genus

Oryx Vol 23 No 1, January 1989 


\section{FFPS news}

Oreomanes are restricted to the quinua woodlands, occurring nowhere else. The large predators, particularly pumas, bears and condors, are persecuted by farmers and the natural herbivores have been largely eliminated for food. The mountain tapir is now extinct there. Bird diversity is very high in the area's cloud forest, including parrots, hummingbirds, Andean pygmy owl and mountain toucan.

The extensive report covers the team's findings in great detail: a comprehensive quantitative survey of the paramo vegetation; an investigation into the effects of burning, trampling and grazing on the paramo vegetation; an investigation of the population dynamics of the quinua woodlands; an assessment of the trout populations; and the provision of information of educational value to the park's administrators for use of the Visitor Information Centre.

\section{Birds in the Yemen Arab Republic}

Grants Committee member Dr Michael Rands of ICBP led a team of 13 biologists from the Ornithological Society of the Middle East who spent two months at the end of 1985 studying the little-known bird life of the Yemen Arab Republic. They gave special attention to (a) the 13 bird species whose global distribution is more or less restricted to Yemen, (b) the conservation status of birds inhabiting the coastal plain and (c) the breeding behaviour and conservation of the Arabian bustard (Yemen is the only country in Arabia with a self-sustaining population).

Their most important recommendations for conservation concern (a) legal protection for all globally-threatened and endemic birds, (b) establishment of a network of protected areas representing all habitat types, (c) development of a conservation education programme and (d) establishment of a Directorate of Wildlife Resources within the Ministry of Agriculture to promote wildlife conservation.

Special consideration is given to five groups of birds among the 346 species occurring in Yemen. Nine species in danger of world-wide extinction occur there of which the bald ibis, lammergeier and white-eyed gull are the most significant. There are 13 species unique to southFFPS news west Arabia, all threatened or vulnerable; some are persecuted by humans, all are threatened by habitat destruction and/or modification. The biological richness of the Red Sea and offshore islands provides an ideal feeding and breeding area for seabirds; in view of pollution and military activities a survey is needed. Freshwater habitats are rare and need protection and management for their rich avifauna. Yemen is an important flyway for raptors ( 32 species in all), especially for steppe eagles, buzzards and black kites; there is little evidence of the direct and indirect persecution that affects raptors in many countries. Over 220 species of passerines have been recorded migrating or wintering.

Following the Expedition ICBP and OSME have worked with the Yemen authorities to implement the recommendations. To date an educational booklet has been drafted with colour illustrations of birds and an Arabic text for distribution to schools, further surveys have been conducted and species protection legislation has been drafted for the parliament to approve.

\section{Kagoro Forest Conservation Study, Nigeria}

In February 1987 Roger Wilkinson and Roger Beecroft, ornithologists, conducted pedal and aerial surveys of the Kagoro and nearby forests in central Nigeria with two other ornithologists (one local), a geographer and a local botanist. They recommend that the relict forests be amalgamated into one area, to protect their fauna and flora; there must be total bans on cultivation, timber felling, burning, livestock grazing and hunting within these forests. Currently-disturbed areas must be allowed to regenerate, and boundaries must be more clearly demarcated. Since valley bottoms provide important corridors for the movement of wildlife between forest blocks, they must also be protected, including riparian woodland, which provides important additional habitat for the larger and more wide-ranging forest birds and primates. An experienced management team is required to ensure that the longterm survival of these forests is placed above the short-term benefits of exploitation, with the Nigerian Conservation Foundation monitoring the status of these forests and encouraging local scientists and students to develop research 


\section{FFPS news}

projects and promote conservation; but educational use must be regulated to prevent excessive disturbance. It is a biologically rich and scenically beautiful area, which merits national park status, substantiated by the detailed botanical and ornithological data presented.

\section{Somalia Research Project}

Following initiation in January 1984, Jane Madgwick and eight colleagues (five local) spent three months of intensive activity in 1986 describing the current status, structure and floristic composition of riverine forest in the Jubba Valley, Somalia. They provided a baseline dryseason study, describing the bird and mammal communities and types and scale of local extractive use, evaluating the changes likely to result from nearby agricultural programmes and providing management guidelines for the area.

Since riverine forest is being lost at a rate of 500 ha/year and their two study sites are the largest, most intact forests in the valley, they recommend that these remaining forests be established as a national monument, because of their values as a national resource and in the maintenance of the riverine ecosystem, as well as in education and research; the agricultural benefit of clearing these forests would be negligible. A wildlife reserve should be developed and a conservation plan should include the protection of undisturbed forest, the regeneration of some degraded forests, the exploitation of others for timber, fuelwood and honey production, and the establishment of a study centre with international support. Improved systems of cultivation, water supply and medical facilities are essential to the success of the wildlife reserve.

\section{A study of the biology and conservation problems of the hispid hare}

Diana Bell of the University of East Anglia spent two months in early 1986 in the Royal Sukla Phanta Wildlife Reserve in western Nepal, studying the behavioural biology of the hispid hare Caprolagus hispidus and collecting comparative data on the rufous-tailed Indian hare Lepus nigricollis ruficaudatus. The hispid hare appeared structurally and behaviourally to be more like a rabbit than a hare, restricting its 56 movements to small areas within dense cover provided by unburnt tall grassland habitat, and having short ears and limbs. Relict populations appear to be seriously at risk because of the management practices, even within protected areas, of burning or harvesting patches of grassland in the dry season, when hispid hares were found by radio-tracking only in the riverine grassland patches that escaped burning. There is a need to develop long-term management plans of maintaining unburned sites and/or having a longer burn cycle; this would increase the diversity of habitats and benefit smaller-bodied species without detriment to large herbivores or village grass requirements. Long-term research programmes are needed to determine the optimum frequencies, timing and extent of burning on a rotational basis to ensure that the relict populations of these species survive.

\section{Oxford University Herpetological Expedition to South India, 1987}

Anita Malhotra led a party of four to the Srivilliputtur Reserve Forest (currently being considered as a Sanctuary by the Indian Government) $40 \mathrm{~km}$ south of Madurai in Tamil Nadu, southern India, during two months in the summer of 1987. Little is known about the herpetofauna of the Western Ghats, the world's oldest mountains. They recorded 9 species of amphibians and 27 species of reptiles, as well as 28 species of butterfly, 51 of birds and 18 of mammals. Their descriptions of snakes, lizards and frogs are augmented by discussion of the fragmentation and reduction of forest habitats, of cattle grazing, burning and poaching (especially of Nilgiri tahr and langurs) and the need to protect the rich and diverse area and to promote public awareness.

\section{Burma 1987}

Jack Frazier spent the statutory week allowed in Burma, restricted mainly to Rangoon, in September 1987. He paints a useful picture about the conservation scenario there, with special reference to chelonians. There are 4 species of sea turtle, 4 of land tortoises, 6 of soft-shelled turtle, 11 of hard-shelled terrapin and 1 snapping

Oryx Vol 23 No 1, January 1989 


\section{FFPS news}

turtle, of which 4 occur only in Burma. Turtles were commonly eaten 100 years ago, and their shells used for various purposes, but there is little sign of them in any of the major markets in Rangoon nowadays, where they are regarded as a symbol of bad luck, greed and disease and thus not eaten. However, this does not apply to all the Burmese peoples: turtle eggs and meat are eaten by coastal peoples, and some jungle tribes devour land turtles. Frazier summarizes what is known about the various species in Burma today. He refers to the 3-year survey by FAO starting in 1981, which yielded a national plan for parks and reserves, which is slowly being implemented. Levels of forest exploitation are unknown, but likely to be similar to other Asian countries, although Burma is unusual among tropical countries in still having 50 per cent of the land area forested. The Burmese Government is showing a commitment to establish national parks, draft wildlife laws and train staff, but there is much political unrest and problems of control. The proposed protected areas, covering all habitat types from rain forests to coral reefs and islands, include known turtle nesting beaches.

\section{Northern Chile 1987}

Chris Hannington spent nearly two months on a study tour of Norte Chico in northern Chile, including the Atacama Desert, in the autumn of 1987. He travelled along the Pan American highway by hired jeep observing a profusion of plants. Because of the low population level and vast undisturbed areas, threats to the native flora appear minimal. Mining and tourism, however, pose potential threats in the future; selling cut flowers by the roadside is a booming business, which will restrict the increase in plant populations; and litter in a dry climate does not decompose readily. Such problems are under control in national parks, but their resources are limited.

\section{Mountain gorilla update}

As regular readers of Oryx are well aware, the FFPS has been involved in the Mountain Gorilla Project since its inception in 1978. The MGP is supported by a consortium of international con-

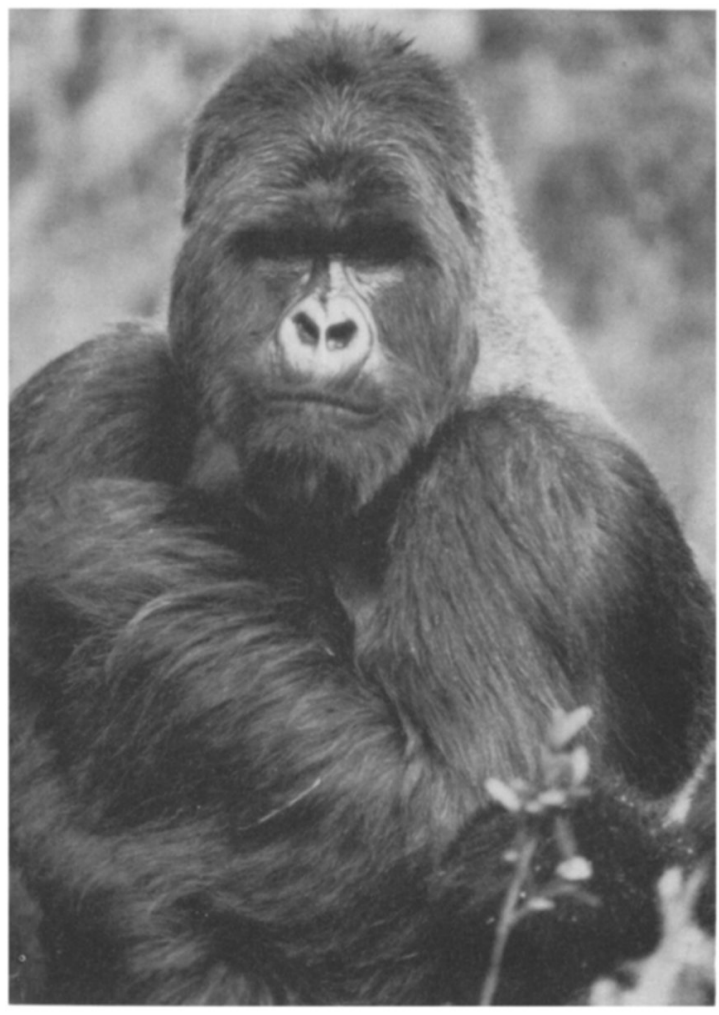

A male silverback mountain gorilla (Craig Sholley/ Mountain Gorilla Project).

servation organizations and is field-managed by the African Wildlife Foundation. The Virunga Veterinary Centre is supported by the Morris Animal Foundation, which is affiliated to the Digit Fund and the Karisoke Research Station. Craig Sholley, the MGP Field-Director, here describes a recent outbreak of illness among the mountain gorilla population, which underlines the fact that, despite the great strides made in their conservation over the past $\mathbf{1 0}$ years, the future of these animals is by no means assured.

The mountain gorillas of the Parc National des Volcans in Rwanda, Africa recently experienced an outbreak of respiratory illness with symptoms including coughs, nasal discharge, and weight loss. Six gorilla deaths occurred between February and May 1988; 27 additional cases were successfully treated and/or monitored.

Tissue and serum samples obtained from ill animals were sent to diagnostic laboratories at the 


\section{FFPS news}

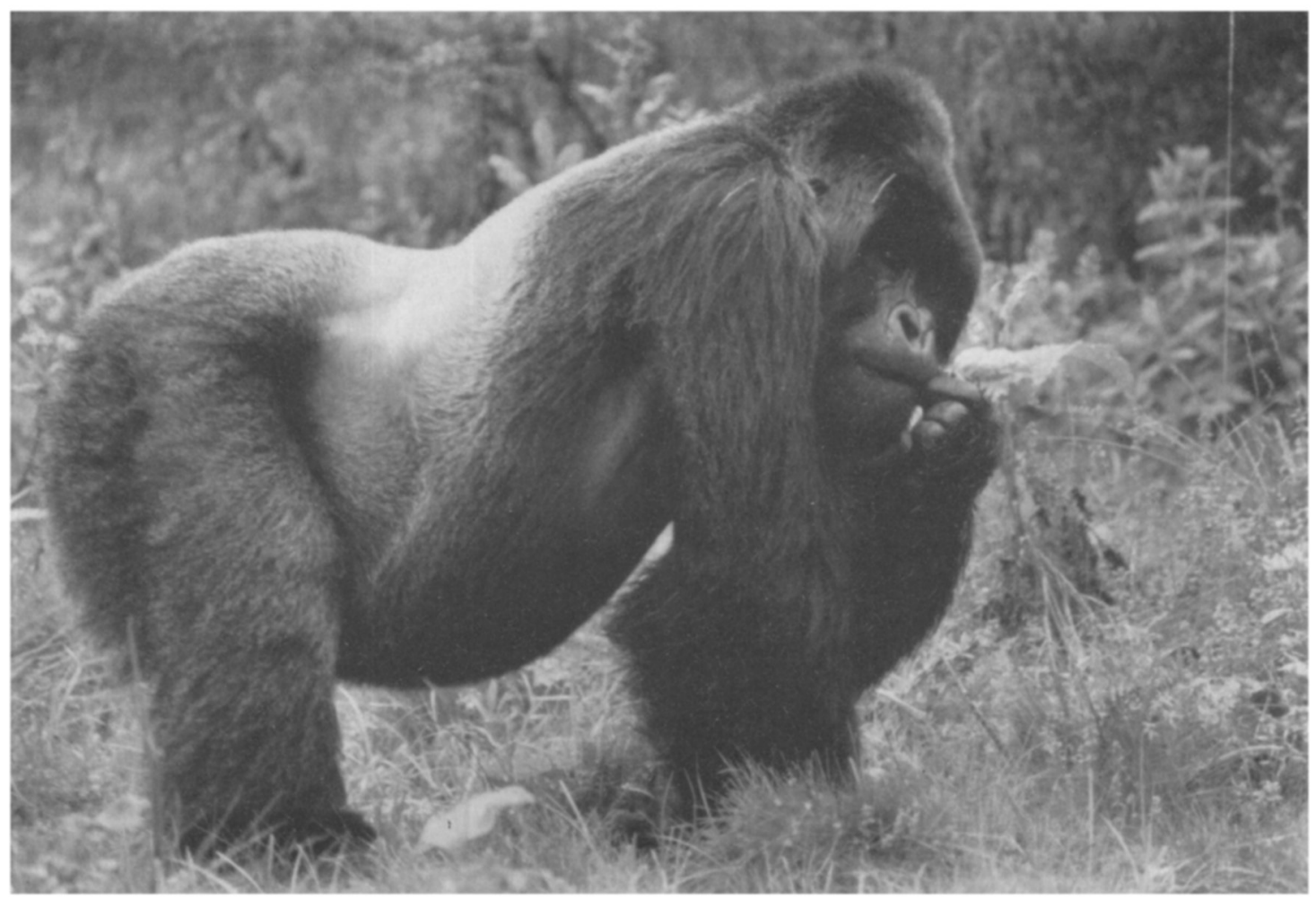

A male silverback gorilla in Rwanda (Craig Sholley/Mountain Gorilla Project).

University of Califormia, Davis Primate Center, the Southwest Foundation for Medical Research, the Pullman Washington Regional Primate Center, and the Zoological Society of London. Analysis results revealed a high likelihood of measles in one expired animal. Causes of death in other animals included kidney disease, pneumonia, and vegetative endocarditis. At least one of the deaths occurred in a gorilla group not experiencing the respiratory outbreak.

The probable existence of one case of measles in the PNV gorilla population prompted the Virunga Veterinary Centre and the Mountain Gorilla Project to jointly design and implement a measles vaccination campaign. A control group of eight free-ranging mountain gorillas, consisting of juvenile, sub-adult, and blackback males were vaccinated and monitored for two weeks. No adverse reactions were noted.

On 29 June, a vaccination campaign began for all gorillas considered eligible for vaccination. Eligible gorillas included all gorillas in study and tourist 58 groups except infants younger than 15 months of age and potentially pregnant females, defined as females with infants older than 2 years 3 months. The measles vaccine was donated by UNICEF, Rwanda, and was administered by simple blowdarting techniques requiring no immobilization. As of 1 September 1988, 95 per cent of eligible gorillas had been successfully vaccinated. No signs of organic disease have been observed in any vaccinated gorilla since the campaign began.

In addition, no cases of respiratory disease have been noted in PNV gorillas since 28 June. Parc National des Volcans activities proceed as usual with an increased emphasis on health surveillance of people using the PNV. On-going preventive health programmes are under consideration for the PNV gorilla population and for all personnel working within the park.

Craig R. Sholley, Director, Mountain Gorilla Project and Barkley Hastings, Virunga Veterinary Centre.

Oryx Vol 23 No 1, January 1989 


\section{FFPS news}

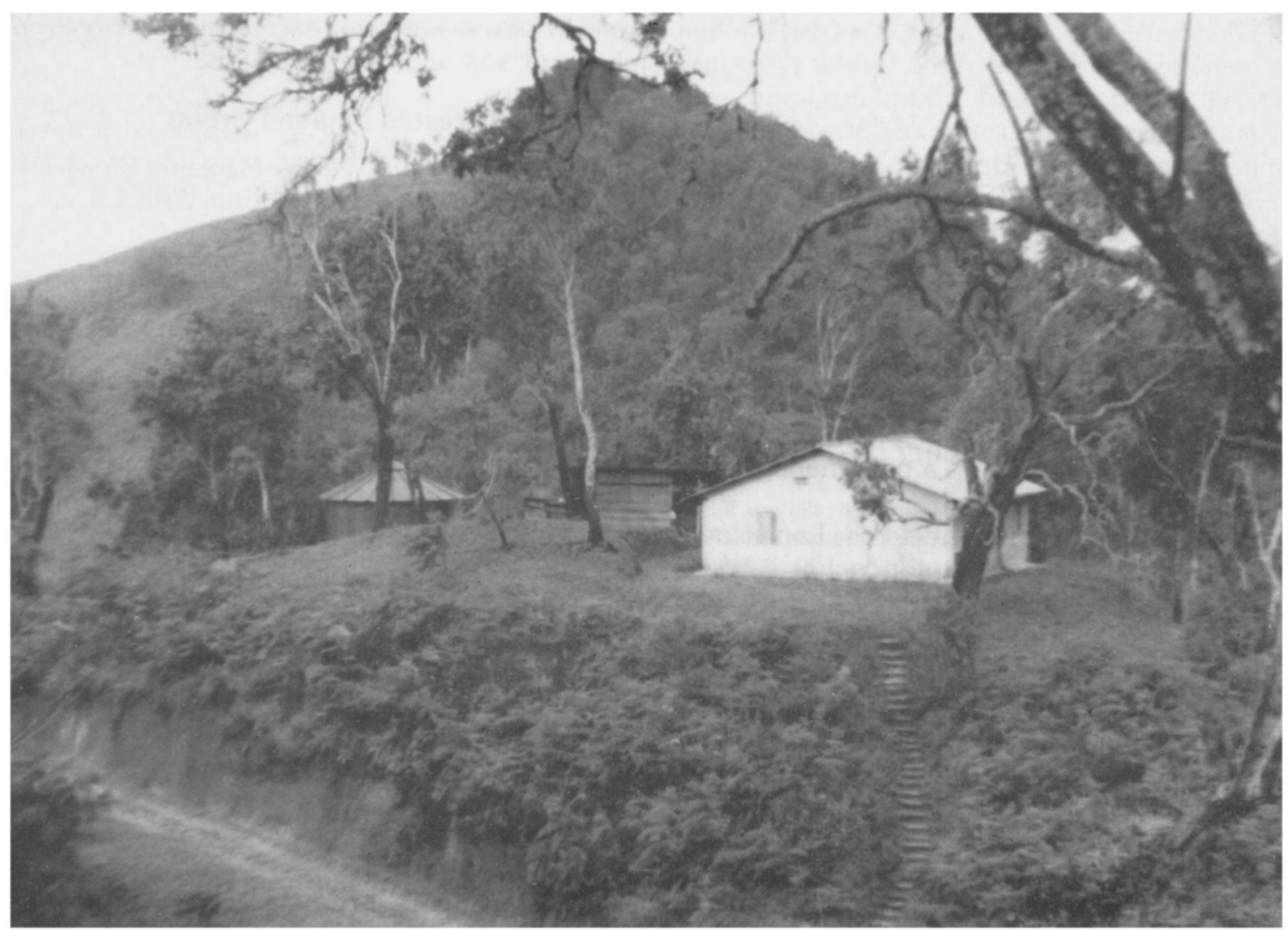

This game guard camp in the Impenetrable Forest, Uganda, was built using FFPS funds in 1988. Money donated by FFPS supporters of the project in 1988 was also used to buy 12 heavy-duty four-man tents, 15 sleeping bags and 20 heavy-duty rucksacks for game guards in Rwanda's Parc National des Volcans (Tom Butynski).

\section{Ele-Fund update}

Two beleaguered populations of East Africa's elephants are now better protected thanks to supporters of The African Ele-Fund, an international appeal launched in the UK in BBC WILDLIFE magazine in November 1987. The EleFund is operating through several renowned conservation organizations (including the FFPS, see Oryx, January 1988, page 68) and so, with no overheads, every penny of every donation is used for practical elephant conservation. More than $£ 15,000$ in donations resulted from the UK launch, and fund-raising activities are now under way in the USA, Canada, West Germany, the Netherlands, Japan and Kenya. Fund-raising also continues in Britain, and Central TV's Nature Watch programme on the work of Dr lain Douglas-Hamilton resulted in a surge of interest and concern.

FFPS news
Thanks are due to the thousands of people worldwide who have already responded, but in the UK I would particularly like to thank FFPS member Miss W. H. Felce, who donated $£ 400$, The Crusade Against All Cruelty to Animals, which raised $£ 1000$, and FFPS Bristol, which raised $£ 130$ during an evening of elephants.

FFPS members are invited to send for a list of elefund-raising ideas and an Ele-Newsletter (please include a stamped addressed envelope). Most of the money raised to date has already been spent in the following ways:

- anti-poaching vehicles have been repaired in the Mount Elgon National Park, Kenya.

- a census of Elgon's unique salt-mining elephants, conducted by Dr J. Shoshani and lan Redmond, has revealed that numbers may be down to as few as 100 (based on observations 
and first-hand reports) but that it is possible that as many as 400 survive in the forests surrounding, but outside, the park boundary (upper estimate based on extrapolation of dung counts in a limited area). This is down from an estimated 1200 in the early 1970s (for a summary of the Elgon crisis see Elephant, 2(3), 46-66). The Kenyan Government plans to increase the park to include much of the surrounding forest, but this welcome move means that even more help is needed from outside agencies if the whole area is to be effectively protected. Further work, to improve the accuracy of the elephant population estimate and help draw up a park management plan, is in the pipeline.

- a reconditioned, long wheel-base Land Rover has been purchased for anti-poacher work in Lake Manyara National Park, Tanzania, and fund-raising is now under way to purchase a second, back-up vehicle.

- 30 drums of aviation fuel have been purchased for use in aerial surveys and anti-poacher reconnaissance in some of Kenya's larger parks.

- A small four-wheel drive vehicle has also been sent to Lake Manyara for researchers to monitor the elephant population, which has more than halved in the last two years as a result of ivory poaching.

Dr Perez Olindo, Director of Kenya's Wildlife Conservation and Management Department, has drawn up a 'shopping list' of urgent requirements so that Ele-Fund-Raisers can target their activities towards the cost of specific items. Please send donations to The African Ele-Fund, c/o FFPS, enclosing a stamped addressed envelope if information or a receipt is required.

Ian Redmond, Co-ordinator, The African EleFund.

\section{Members' meetings London meetings}

Details of the London meetings, held at the Zoological Society of London's meeting rooms, are given in the insert of this issue of Oryx.

Some local group meetings are listed below; others are also being arranged, but full details were not available when going to press. For information about additional meetings please write 60 to the address given for each group, enclosing a stamped, self-addressed envelope.

\section{Bristol and West of England Group}

Ian Redmond, c/o BBC Wildlife Magazine, Broadcasting House, Whiteladies Road, Bristol BS8 2LR.

\section{Cambridge Group}

17 February 1989 (with Cambridge Natural History Society and Cambridge Wildlife Trust). 'Lead and Swans-the Real Story' with Dr Jane Sears and Dr Chris Spray, scientists from Oxford University and Anglia Water, respectively.

5 May 1989. 'One for All and All for One' or 'Meerkats United' with Dr David MacDonald of Oxford University.

Meetings are held at the Department of Zoology, New Museum Site, Downing Street, Cambridge and start at 6.00 p.m. with a buffet supper with wine (cost $£ 3.00$, only by pre-booked ticket, available from Dr Sandy Harcourt, LARG, Department of Zoology, Downing Street, Cambridge CB2 3EJ). Talks start at 7.30 p.m., at which attendance is free.

\section{Oxford Group}

David Macdonald, Department of Zoology, University of Oxford, South Parks Road, Oxford OX1 3PS.

\section{North-West Group}

Nick Ellerton, Chester Zoo, Caughall Road, Upton, Chester $\mathrm{CH} 2$ 1LH.

\section{Edinburgh Group}

19 January 1989 at 7.30 p.m. Joint meeting with Edinburgh Zoo at the zoo's Education Centre. 'The Organization of International Conservation', a talk by $\mathrm{Dr}$ Robin Pellew, Director of the Conservation Monitoring Centre, IUCN. Cost 40p, including coffee and biscuits.

8 April 1989 at 2.0 p.m. Joint visit with the Scottish Wildlife Trust to Bawsinch Reserve and Duddington Loch. Meet at Dunsapie Loch Car Park, Holyrood Park, Edinburgh at 1.30 p.m.

22 September 1989 at 7.30 p.m. Joint meeting with the Scottish Herpetological Society at the Education Centre, Edinburgh Zoo. A talk by Mike Linley from Anglia Television. Cost $£ 1.50$, including coffee and biscuits.

Mrs Ingrid Stewart, Edinburgh Zoo, Murrayfield, Edinburgh EH12 6TS. Telephone 0313349171.

Oryx Vol 23 No 1, January 1989 